\title{
Aortic valve leaflet and root dimensions in normal tricuspid aortic valves: a computed tomography study
}

\author{
Matija Jelenc ${ }^{1}$, Blaž Jelenc ${ }^{2}$, Gregor Poglajen ${ }^{1}$, and Nikola Lakič ${ }^{1}$ \\ ${ }^{1}$ Univerzitetni Klinični Center Ljubljana \\ ${ }^{2}$ Univerza v Ljubljani Fakulteta za matematiko in fiziko
}

January 31, 2022

\begin{abstract}
Background and aim of the study Objective of this analysis was to use coronary computed tomography in patients with normal tricuspid aortic valves to perform detailed aortic root and aortic valve geometric analysis with focus on asymmetry of the three leaflets. Materials and methods We analyzed aortic valves in 70 anonymized coronary computed tomography angiograms. Mean patient age was $53 \pm 11$ years. All aortic valves were tricuspid, without calcifications and aortic roots were of normal dimensions. Asymmetry of the three leaflets in individual patients was assessed by calculating absolute and relative differences between the largest and the smallest of the three leaflets. Results Some degree of asymmetry was present in all analyzed valves. Absolute and relative differences for free margin length were $3.2 \pm 1.4 \mathrm{~mm}$ and $9.3 \pm 3.8 \%$, respectively. The largest relative difference was noted in coaptation area $(36.5 \pm 16.5 \%)$ and the smallest in leaflet effective height $(6.1 \pm 4.8 \%)$. Using predefined cut-off criteria for absolute differences in leaflet dimensions, $86 \%$ of the valves were classified as asymmetric. Conclusions Equal free margin length of the three leaflets is not needed for normal tricuspid aortic valve function. Aligning the leaflet free margin length in standardized aortic valve repair may not be necessary in tricuspid aortic valve repair, whereas equalization of effective leaflet heights is.
\end{abstract}

\section{TITLE PAGE}

Title : Aortic valve leaflet and root dimensions in normal tricuspid aortic valves: a computed tomography study

Running title: Asymmetry of aortic valve leaflets

Authors: Matija Jelenc ${ }^{1}$, Blaž Jelenc ${ }^{2}$, Gregor Poglajen ${ }^{3,4}$, Nikola Lakič ${ }^{1}$

\section{Institutions:}

${ }^{1}$ Department for Cardiovascular Surgery, University Medical Center Ljubljana, Slovenia

${ }^{2}$ Faculty of Mathematics and Physics, University of Ljubljana, Slovenia

${ }^{3}$ Advanced Heart Failure and Transplantation Program, Department of Cardiology, University Medical Center Ljubljana, Slovenia

${ }^{4}$ Department of Internal Medicine, Faculty of Medicine, University of Ljubljana

\section{Corresponding author:}

Matija Jelenc, MD, PhD

University Medical Center Ljubljana, Department for Cardiovascular Surgery

Zaloška 7, 1000 Ljubljana, Slovenia 
$\mathrm{T}:+38615224941$

E: jelenc@gmail.com

Meeting presentation:

Abstract of preliminary results of this study was presented at $34^{\text {th }}$ EACTS annual meeting in Barcelona 2020 .

Word count: 4492

Funding statement

This work was supported by a research grant of the University Medical Center Ljubljana [grant number 20190174].

\section{Conflict of interest statement}

None declared.

\section{Author contribution statement}

MJ - conceptualization, data curation, funding acquisition, methodology, software, writing - original draft

BJ - data curation, formal analysis, methodology, software, visualization

GP - formal analysis, supervision, validation, writing - review and editing

$\mathrm{NL}$ - funding acquisition, methodology, project administration, resources, supervision, writing - review and editing

\section{Data availability statement}

Data available on request.

\section{ABSTRACT}

\section{Background and aim of the study}

Objective of this analysis was to use coronary computed tomography in patients with normal tricuspid aortic valves to perform detailed aortic root and aortic valve geometric analysis with focus on asymmetry of the three leaflets.

\section{Materials and methods}

We analyzed aortic valves in 70 anonymized coronary computed tomography angiograms. Mean patient age was $53 \pm 11$ years. All aortic valves were tricuspid, without calcifications and aortic roots were of normal dimensions. Asymmetry of the three leaflets in individual patients was assessed by calculating absolute and relative differences between the largest and the smallest of the three leaflets.

\section{Results}

Some degree of asymmetry was present in all analyzed valves. Absolute and relative differences for free margin length were $3.2 \pm 1.4 \mathrm{~mm}$ and $9.3 \pm 3.8 \%$, respectively. The largest relative difference was noted in coaptation area $(36.5 \pm 16.5 \%)$ and the smallest in leaflet effective height $(6.1 \pm 4.8 \%)$. Using predefined cut-off criteria for absolute differences in leaflet dimensions, $86 \%$ of the valves were classified as asymmetric.

\section{Conclusions}

Equal free margin length of the three leaflets is not needed for normal tricuspid aortic valve function. Aligning the leaflet free margin length in standardized aortic valve repair may not be necessary in tricuspid aortic valve repair, whereas equalization of effective leaflet heights is.

\section{KEYWORDS}


Aortic valve anatomy; Aortic valve repair; Computed tomography; 3d modelling

\section{TEXT}

\section{Introduction}

One of the steps in standardized aortic valve repair is alignment of leaflet free margin lengths ${ }^{1}$. This step is crucial in bicuspid aortic valve repair, where only two leaflets coapt and must have identical free margin length for the valve to be competent. However, clinical experience shows that tricuspid aortic valves can be very asymmetric in terms leaflet size and free margin length but still function normally ${ }^{2}$. In tricuspid aortic valves equal effective leaflet height appears to be more important than equal free margin length ${ }^{3,4}$. The primary aim of the present study was to use coronary computed tomography angiography (CTA) in patients with normal tricuspid aortic valves to perform detailed aortic root and aortic valve geometric analysis with a focus on asymmetry of the three leaflets.

\section{Materials and Methods}

The study was approved by the National Medical Ethics Committee (NMEC; Komisija Republike Slovenije za medicinsko etiko, No. 0120-133/2021/3, 14.5.2021). Written patient informed consent was waived by NMEC as this was a non-interventional study.

We analyzed 127 anonymized coronary CTAs from our hospital's picture archiving and communication system (PACS). The anonymized CTAs included gender, age, height, and weight of the patient in the metadata. 57 CTAs were excluded from further analysis due to one or more of the following reasons: bicuspid aortic valve, poor contrast, poor leaflet visibility, motion artefacts, calcifications of aortic valve leaflets, and aortic root diameter [?] $45 \mathrm{~mm}$. On the remaining 70 CTAs all aortic valves were tricuspid, without calcifications and the diameter of aortic root was $<45 \mathrm{~mm}$. All valve analyses were performed in end-diastolic phase of the cardiac cycle. The CTAs were imported into Mimimics Innovation Suite v. 21.0 (Materialise, Leuven, Belgium) where aortic roots were segmented. Several geometric points of interest (Fig. 1) were marked on each segmented aortic root in 3D space. Spline tool was used to define coaptation surfaces, leaflet attachments, commissural heights and annular and sinutubular perimeters for each patient. The points and splines defined by 3D coordinates were then imported into Mathematica v12.0 (Wofram Research, UK) where dedicated code was used to reconstruct the aortic valve in 3D space from the measured points and splines, define different planes, calculate relevant angles, lengths, and areas for each patient. Central coaptation point was calculated as a mean of the tips of the three geometric height splines.

Asymmetry of the three leaflets in individual patients was assessed by calculating absolute and relative differences. Absolute difference for selected measurement was defined as difference between the largest and the smallest of the three leaflets. Relative difference for selected measurement was defined as absolute difference divided by the mean of the three leaflets.

Statistical data analysis was performed using JASP v 0.14.1 (University of Amsterdam, Netherlands). Normal distribution of variables was assessed using the Shapiro-Wilk test. Continuous variables are reported as mean +- standard deviation. Differences were analyzed using Independent samples t-test and Repeated measures ANOVA with post hoc test with Bonferroni correction. In analysis of asymmetry One sample $\mathrm{t}$ - test and Wilcoxon signed-rank test were used. P-value of less than 0.05 was considered statistically significant.

\section{Results}

Baseline patient and aortic valve data are presented in Table 1,2 and 3, and are graphically summarized in Figures 2 and 3, where measurements are normalized to either annular mean diameter to allow comparison to data published by Swanson and Clark ${ }^{5}$ or to mean leaflet geometric height to allow comparison to data published by De Kerchove et $\mathrm{al}^{6}$.

Mean age of patients was $53+-11$ years, with no difference between men and women (Table 1), $50 \%$ of patients $(\mathrm{n}=35)$ were female. Men were higher and heavier, with larger aortic valves (larger annular 
diameter, sinutubular junction diameter and all leaflet dimensions), however the geometry of aortic root and leaflets was similar (all angles as well as normalized dimensions were similar) (Table 2). The right coronary leaflet had the longest mean free margin length $(35.2+-4.1 \mathrm{~mm})$ and intercommissural distance $(25.1+-3.0$ $\mathrm{mm})$, whereas the noncoronary leaflet had the longest mean geometric height $(16.5+-2.0 \mathrm{~mm})$ and leaflet attachment length $(51.7+-6.6 \mathrm{~mm})$. Right-noncoronary commissure was the highest of the three $(20.6+-$ $3.0 \mathrm{~mm}$ ). Mean valve height calculated as the distance between annular and sinutubular plane centroids was $19.2+-2.2 \mathrm{~mm}$ and the central coaptation point of the three leaflets was located at $46 \%$ of the distance between annular and sinutubular plane, starting from the annular plane. Mean effective leaflet height was $8.5+-1.4 \mathrm{~mm}$, and there were no significant differences between the three leaflets. Mean angle between annular plane and sinutubular plane was $7.8+-3.9$ degrees (Table 3). Noncoronary leaflet occupied the smallest angle relative to the sinutubular plane $(116+-6$ degrees $)$.

Asymmetry of the three cups in individual patients is summarized in Table 4. All absolute and relative differences between the three leaflets were significantly larger than zero. Absolute and relative differences for free margin length were $3.2+-1.4 \mathrm{~mm}$ and $9.3+-3.8 \%$, respectively. The largest relative difference was noted in coaptation area $(36.5+-16.5 \%)$ and the smallest in leaflet effective height $(6.1+-4.8 \%)$. Using the cut-off values for absolute differences in free margin length, geometric height, intercommissural distance, and leaflet attachment length defined by De Kerchove et $\mathrm{al}^{6}$ aortic valves were classified into symmetric and asymmetric (Table 5). Using each of these criteria separately, on average $42 \%$ of the valves were classified as asymmetric. However, observing all four criteria at once, only $10(14 \%)$ valves were symmetric and 60 (86\%) had at least one criterion for asymmetry (28 (40\%) had one criterion, 14 (20\%) had two criteria, 11 $(16 \%)$ had three criteria, and $7(10 \%)$ had all four criteria for asymmetry).

\section{Discussion}

There are several advantages of using coronary CTA in morphologic aortic valve analysis. Aortic valves are observed in vivo in diastole, pressurized with physiologic diastolic pressure with all the surrounding structures intact. Unlike in anatomical studies where tissues are fixed with glutaraldehyde ${ }^{5,6}$ the mechanical properties of leaflets and root in our study were not altered. Measurements performed on the segmented root in 3D space allow definition of different points, lines, planes, angles and relationships, some of which cannot be done on anatomical models.

The mean age of patients was 53 years, which reflects the age of patients referred to coronary CTA, as coronary artery disease is rare in younger patients. However, another reason to preferentially choose older patients is visibility of aortic leaflets. Some of the CTAs of young patients that were provided by our radiology service were rejected simply because aortic leaflets were very thin and hardly visible on the CTA. It seems that with aging leaflets thicken, which increases visibility on CTA.

The patients in our study had normal tricuspid aortic valves and normal root dimensions as in the study on homografts by De Kerchove et $\mathrm{al}^{6}$. In both studies the right-noncoronary commissure was the highest (20.6 $+-3.0 \mathrm{~mm}$ in our study vs. $21.8+-2.1 \mathrm{~mm}$ ), although intraoperatively it appears to be the lowest one as external root dissection is limited in this area due to right atrial attachment and membranous septum. Mean free margin length was almost identical (34.0 +- $4.0 \mathrm{~mm}$ in our study vs $34.4+-3.1 \mathrm{~mm})$, longest in the right aortic leaflet and shortest in the left aortic leaflet. Similar relationship was found in intercommissural distances. Mean geometric leaflet height was shorter in our study $(15.9+-1.6 \mathrm{~mm}$ vs $18.9+-1.5 \mathrm{~mm})$, with both studies showing longest geometric height in noncoronary leaflet, similar to study by Schafers et $\mathrm{al}^{7}$. The reason for this difference may be different body size of patients and different methodology of measurement. In a Japanese study ${ }^{8}$ with similar methodology mean geometric height was $14.7 \mathrm{~mm}$ with mean body surface area of $1.7 \mathrm{~m}^{2}$, whereas mean body surface area in our study was $1.9 \mathrm{~m}^{2}$. On CTA, geometric height is measured in diastole with aortic valve closed, whereas in homografts or intraoperatively the leaflet is placed under tension during geometric height measurement. A difference of $1.7 \mathrm{~mm}$ between preoperative CTA and intraoperative measurements of geometric size was found in a study by Komiya T et $\mathrm{al}^{9}$. Longer intraoperative geometric leaflet height was also found in a study by Schafers et $\mathrm{al}^{7}$, however, some of the difference may be attributed to the fact that measurements were performed on patients with 
aortic valve and root pathology, where leaflet distension may occur ${ }^{10}$. Coaptation surfaces were larger in our study, with the largest surface on the right coronary leaflet, a finding similar to De Kerchove et $\mathrm{al}^{6}$. However, as coaptation surface is often difficult to delineate on CTA as it may not lie in a single plane, this measurement should be interpreted carefully as it is prone to error. Central coaptation length was also similar $(3.7+-0.6 \mathrm{~mm}$ in our study vs $3.3+-0.8 \mathrm{~mm})$. When normalized to geometric height we found all dimensions longer than data published by De Kerchove et $\mathrm{al}^{6}$, which probably reflects the relatively shorter mean geometric height.

Normalizing root and leaflet dimensions to annulus diameter gave results comparable to the study by Swanson and Clark $^{5}$ with aortic valve casts made at pressure of $100 \mathrm{mmHg}$. Some dimensions such as geometric height and central coaptation length were somewhat smaller, however normalized sinutubular diameter was larger (1.13 vs 1.0) and one half of free margin length was longer (0.69 vs 0.62$)$ in our study. Leaflet belly to annulus angle was similar (24 degrees vs 22 degrees) as well as free margin to sinutubular plane angle (37 degrees vs 32 degrees). One explanation could be the higher age of our patients $(53+-11$ years vs $35+-6$ years) causing the increase in sinutubular junction diameter and longer free margin length.

All aortic valves displayed some degree of asymmetry. Absolute differences between the three leaflets of individual patients were very similar to data published by De Kerchove et $\mathrm{al}^{6}$. Absolute difference in free margin length $3.2+-1.4 \mathrm{~mm}$ vs $3.1+-1.4 \mathrm{~mm}$, in intercommissural distance $2.6+-1.1 \mathrm{~mm}$ vs $3.6+-1.7$ $\mathrm{mm}$, in geometric height $2.5+-1.3 \mathrm{~mm}$ vs $1.9+-1.0$, and in leaflet attachment length $4.0+-2.1 \mathrm{~mm}$ vs $5.0+-2.3 \mathrm{~mm}$. Using predefined cut-off values for absolute differences in leaflet dimensions and observing a single leaflet dimension at once, on average $42 \%$ of valves in our study were classified as asymmetric, whereas approximately $54 \%$ were asymmetric in the study by De Kerchove et $\mathrm{al}^{6}$. However, when observing all four leaflet dimensions at once, $86 \%$ of valves were asymmetric in at least one of the four selected dimensions. In a study by Vollebergh et $\mathrm{l}^{11}$ on 200 cadavers with normal tricuspid aortic valves they found that only 5 had leaflets of equal geometric size and intercommissural distance. Similarly, asymmetry of the leaflet surface areas, intercommissural distances and sinus of Valsalva volumes was found in a computed tomography study by Yang $\mathrm{DH}$ et $\mathrm{al}^{12}$. In a completely symmetric aortic valve, all leaflet measurements would be identical, however the two anatomical facts, that annulus plane and commissural plane are not parallel and that left ventricular outflow is elliptical result in small differences in commissural heights, leaflet dimensions and angles ${ }^{8}$. Effective height, however, showed the least amount of asymmetry - on average only $6 \%(0.5 \mathrm{~mm})$, which explains its importance in keeping the aortic valve competent.

The main limitations of CTA were contrast and resolution. Ideally, there was a lot of contrast in the aorta and left ventricle but much less in the right side of the heart and pulmonary circulation. In these cases, the aortic root segmentation was fast and straightforward. When this was not the case, segmentation was prolonged because the structures surrounding the root needed to be removed manually. The second issue was visibility of aortic leaflets. Particularly in young patients the leaflets are normally very thin and may not be clearly visible on CTA. Consequently, the least reliable measurement in our study were the coaptation areas between the leaflets, which may not even lie in a single plane and are sometimes difficult to visualize. Another limitation is a relatively small sample size of the study.

\section{Conclusion}

Asymmetry in tricuspid aortic valves is normal and was present in all valves we analyzed. Using cut-off criteria for absolute differences in leaflet dimensions $86 \%$ of the valves were classified as asymmetric.

Aligning the leaflet free margin length in standardized aortic valve repair may not be necessary in tricuspid aortic valve repair ${ }^{13,14}$. It seems that in tricuspid aortic valves the same effective height of the three cups is more important than identical free margin length, whereas in bicuspid aortic valves, aligning the free margin length of both leaflets is crucial.

There is a need for the development of surgical techniques that would respect the asymmetry, particularly in reimplantation and remodeling procedures. Respecting asymmetry in very asymmetric cases is mandatory ${ }^{2}$, whereas in less asymmetric cases it may reduce the need for leaflet plication and impact long-term results. 


\section{Tables}

Table 1. Patient data and aortic valve measurements.

\begin{tabular}{l}
\hline Parameters \\
\hline Age (years), mean $\pm \mathrm{SD}$ \\
Male gender, n $(\%)$ \\
Weight $(\mathrm{kg})$, mean $\pm \mathrm{SD}$ \\
Height $(\mathrm{cm})$, mean $\pm \mathrm{SD}$ \\
Body surface area ${ }^{4}\left(\mathrm{~m}^{2}\right)$, mean $\pm \mathrm{SD}$ \\
Annular diameter - perimeter based $(\mathrm{mm})$, mean $\pm \mathrm{SD}$ \\
Sinutubular junction diameter $(\mathrm{mm})$, mean $\pm \mathrm{SD}$ \\
Commissural height $(\mathrm{mm})$, mean $\pm \mathrm{SD}$
\end{tabular}

Intercommissural distance (mm), mean $\pm \mathrm{SD}$

Leaflet attachment length $(\mathrm{mm})$, mean $\pm \mathrm{SD}$

Free margin length $(\mathrm{mm})$, mean $\pm \mathrm{SD}$

Valve height $(\mathrm{mm})$, mean $\pm \mathrm{SD}$

Geometric height $(\mathrm{mm})$, mean $\pm \mathrm{SD}$

Coaptation area between two adjacent leaflets $\left(\mathrm{mm}^{2}\right)$, mean $\pm \mathrm{SD}$

Central coaptation length $(\mathrm{mm})$, mean $\pm \mathrm{SD}$

Effective height $(\mathrm{mm})$, mean $\pm \mathrm{SD}$

Distance between central coaptation point and annular plane relative to valve height, mean \pm SD
Parameters

Age (years), mean $\pm \mathrm{S}$

Male gender, n (\%)

Weight $(\mathrm{kg})$, mean $\pm \mathrm{S}$

Height $(\mathrm{cm})$, mean $\pm \mathrm{S}$

Body surface area ${ }^{4}\left(\mathrm{~m}^{2}\right.$

Annular diameter - per

Sinutubular junction di

Commissural height $(\mathrm{m}$

$\mathrm{R} / \mathrm{L}$ commissure

$\mathrm{L} / \mathrm{N}$ commissure

$\mathrm{R} / \mathrm{N}$ commissure

Intercommissural distal

Right leaflet

Left leaflet

Noncoronary leaflet

Leaflet attachment leng

Right leaflet

Left leaflet

Noncoronary leaflet

Free margin length (mr

Right leaflet

Left leaflet

Noncoronary leaflet

Valve height (mm), me Geometric height $(\mathrm{mm})$

Right leaflet

Left leaflet

Noncoronary leaflet

Coaptation area betwee

$\mathrm{R} / \mathrm{L}$ coaptation area

$\mathrm{L} / \mathrm{N}$ coaptation area

$\mathrm{R} / \mathrm{N}$ coaptation area

Central coaptation leng

Effective height (mm),

Right leaflet

Left leaflet

Noncoronary leaflet

Distance between centr

$* \mathrm{M}$ vs $\mathrm{F}$ - male versus female

$\mathrm{R}$ - right, L - left, $\mathrm{N}$ - noncoronary

${ }^{1}$ Repeated measures ANOVA

${ }^{2}$ Post Hoc test with Bonferroni correction

${ }^{3}$ Independent samples t-test 
${ }^{4}$ Mosteller formula was used to calculate body surface area

Table 2. Gender differences in aortic valve dimensions.

\begin{tabular}{|c|c|c|c|}
\hline Parameters & Men $(\mathrm{n}=35)$ & Women $(\mathrm{n}=35)$ & $\mathrm{P}$-value \\
\hline Weight $(\mathrm{kg})$, mean $\pm \mathrm{SD}$ & $86 \pm 11$ & $66 \pm 10$ & $<0.001^{1}$ \\
\hline Height $(\mathrm{cm})$, mean $\pm \mathrm{SD}$ & $178 \pm 8$ & $166 \pm 7$ & $<0.001^{1}$ \\
\hline Body surface $\operatorname{area}^{2}\left(\mathrm{~m}^{2}\right)$, mean $\pm \mathrm{SD}$ & $2.06 \pm 0.16$ & $1.74 \pm 0.15$ & $<0.001^{1}$ \\
\hline Annular diameter $(\mathrm{mm})$, mean $\pm \mathrm{SD}$ & $26.3 \pm 2.1$ & $23.2 \pm 2.2$ & $<0.001^{1}$ \\
\hline Sinutubular junction diameter $(\mathrm{mm})$, mean $\pm \mathrm{SD}$ & $29.4 \pm 2.8$ & $26.3 \pm 2.5$ & $<0.001^{1}$ \\
\hline Mean leaflet attachment length $(\mathrm{mm})$, mean $\pm \mathrm{SD}$ & $54.9 \pm 4.5$ & $47.4 \pm 4.3$ & $<0.001^{1}$ \\
\hline Mean geometric height $(\mathrm{mm})$, mean $\pm \mathrm{SD}$ & $17.0 \pm 1.2$ & $15.0 \pm 1.3$ & $<0.001^{1}$ \\
\hline Mean commissural height $(\mathrm{mm})$, mean $\pm \mathrm{SD}$ & $20.6 \pm 1.9$ & $17.9 \pm 1.7$ & $<0.001^{1}$ \\
\hline Mean free margin length $(\mathrm{mm})$, mean $\pm \mathrm{SD}$ & $36.3 \pm 3.3$ & $31.8 \pm 3.2$ & $<0.001^{1}$ \\
\hline Mean intercommissural distance $(\mathrm{mm})$, mean $\pm \mathrm{SD}$ & $25.4 \pm 2.4$ & $22.7 \pm 2.2$ & $<0.001^{1}$ \\
\hline Mean leaflet belly to annular plane angle $\left(^{\circ}\right)$, mean \pm SD & $24.2 \pm 6.5$ & $24.2 \pm 5.1$ & $0.979^{1}$ \\
\hline Mean free margin to sinutubular plane angle $\left(^{\circ}\right)$, mean $\pm \mathrm{SD}$ & $37.5 \pm 4.8$ & $36.1 \pm 5.1$ & $0.240^{1}$ \\
\hline Normalized mean geometric height, mean $\pm \mathrm{SD}^{*}$ & $0.65 \pm 0.04$ & $0.65 \pm 0.04$ & $0.789^{1}$ \\
\hline Normalized sinutubular junction diameter, mean $\pm \mathrm{SD}^{*}$ & $1.13 \pm 0.12$ & $1.14 \pm 0.09$ & $0.672^{1}$ \\
\hline Normalized mean free margin length, mean $\pm \mathrm{SD}^{*}$ & $1.38 \pm 0.12$ & $1.37 \pm 0.07$ & $0.622^{1}$ \\
\hline Normalized effective height, mean $\pm \mathrm{SD}^{*}$ & $0.35 \pm 0.07$ & $0.35 \pm 0.06$ & $0.298^{1}$ \\
\hline Normalized valve height, mean $\pm \mathrm{SD}^{*}$ & $0.79 \pm 0.08$ & $0.77 \pm 0.05$ & $0.869^{1}$ \\
\hline
\end{tabular}

*Data are normalized to annular diameter

${ }^{1}$ Independent samples t-test

${ }^{2}$ Mosteller formula was used to calculate body surface area

Table 3. Aortic valve angles.

\begin{tabular}{ll}
\hline Parameters & Parameters \\
\hline Leaflet belly to annular plane angle $\left(^{\circ}\right)$, mean $\pm \mathrm{SD}$ & Leaflet belly to annular plane angle $\left(^{\circ}\right)$, \\
& Right leaflet \\
& Left leaflet \\
Free margin to sinutubular plane angle $\left({ }^{\circ}\right)$, mean $\pm \mathrm{SD}$ & Noncoronary leaflet \\
& Free margin to sinutubular plane angle \\
& $\mathrm{R} / \mathrm{L}$ commissure \\
Angle occupied by individual leaflet relative to sinutubular plane $\left(^{\circ}\right)$, mean $\pm \mathrm{SD}$. & Angle occupied by individual leaflet rele \\
& Right leaflet \\
& Left leaflet \\
Sinutubular to annular plane angle $\left(^{\circ}\right)$, mean $\pm \mathrm{SD}$ & Noncoronary leaflet \\
& Sinutubular to annular plane angle $\left(^{\circ}\right)$,
\end{tabular}

${ }^{*} \mathrm{M}$ vs $\mathrm{F}-$ male versus female

$\mathrm{R}$ - right, $\mathrm{L}$ - left, $\mathrm{N}$ - noncoronary

${ }^{1}$ Repeated measures ANOVA 
${ }^{2}$ Post Hoc test with Bonferroni correction

Table 4. Asymmetry of the three leaflets shown by absolute and relative differences in various measurements of the three leaflets in individual patients.

\begin{tabular}{|c|c|c|}
\hline & Absolute difference $\pm \mathrm{SD}$ (range)* & Relative differe \\
\hline Leaflet attachment length (mm) & $4.0 \pm 2.1(0.4-10.8)^{2}$ & $7.7 \pm 3.8(0.8-$ \\
\hline Geometric height $(\mathrm{mm})$ & $2.5 \pm 1.3(0.4-6.0)^{2}$ & $16.0 \pm 8.2(2.3$ \\
\hline Effective height (mm) & $0.5 \pm 0.5(0.0-2.9)^{2}$ & $6.1 \pm 4.8(0.1-$ \\
\hline Free margin length $(\mathrm{mm})$ & $3.2 \pm 1.4(0.4-6.6)^{2}$ & $9.3 \pm 3.8(1.3-$ \\
\hline Coaptation area $\left(\mathrm{mm}^{2}\right)$ & $30.1 \pm 14.9(0.5-76.2)^{2}$ & $36.5 \pm 16.5(0.7$ \\
\hline Commissural height (mm) & $2.9 \pm 1.7(0.4-8.6)^{2}$ & $15.0 \pm 8.0(2.3$ \\
\hline Intercommissural distance ( $\mathrm{mm})$ & $2.6 \pm 1.1(0.2-6.3)^{2}$ & $10.8 \pm 3.8(1.0$ \\
\hline Leaflet belly to annular plane angle $\left(^{\circ}\right)$ & $6.9 \pm 3.7(0.9-17.3)^{2}$ & $29.2 \pm 15.2(4.5$ \\
\hline Free margin to sinutubular plane angle $\left(^{\circ}\right)$ & $6.9 \pm 2.8(0.4-13.8)^{1}$ & $19.0 \pm 7.5(1.1$ \\
\hline Angle occupied by individual leaflet relative to sinutubular plane $\left({ }^{\circ}\right)$ & $12.3 \pm 6.7(1.3-34.4)^{2}$ & $10.3 \pm 5.6(1.1$ \\
\hline
\end{tabular}

*Absolute difference for selected measurement is the difference between the largest and the smallest of the three leaflets. Relative difference for selected measurement is defined as absolute difference divided by the mean of the three leaflets.

${ }^{1}$ One sample $t$ - test

${ }^{2}$ Wilcoxon signed-rank test

Table 5. Symmetry defined by cut-off values in absolute differences between the three leaflets.

\begin{tabular}{lll}
\hline Leaflet dimension & Absolute difference criteria for symmetry & N (\%) of asymmetric valves \\
\hline Free margin length & $<3 \mathrm{~mm}$ & $34(49 \%)$ \\
Geometric height & $<2 \mathrm{~mm}$ & $40(57 \%)$ \\
Intercommissural distance & $<3 \mathrm{~mm}$ & $22(31 \%)$ \\
Leaflet attachment length & $<5 \mathrm{~mm}$ & $21(30 \%)$ \\
\hline
\end{tabular}

Figures and figure legends
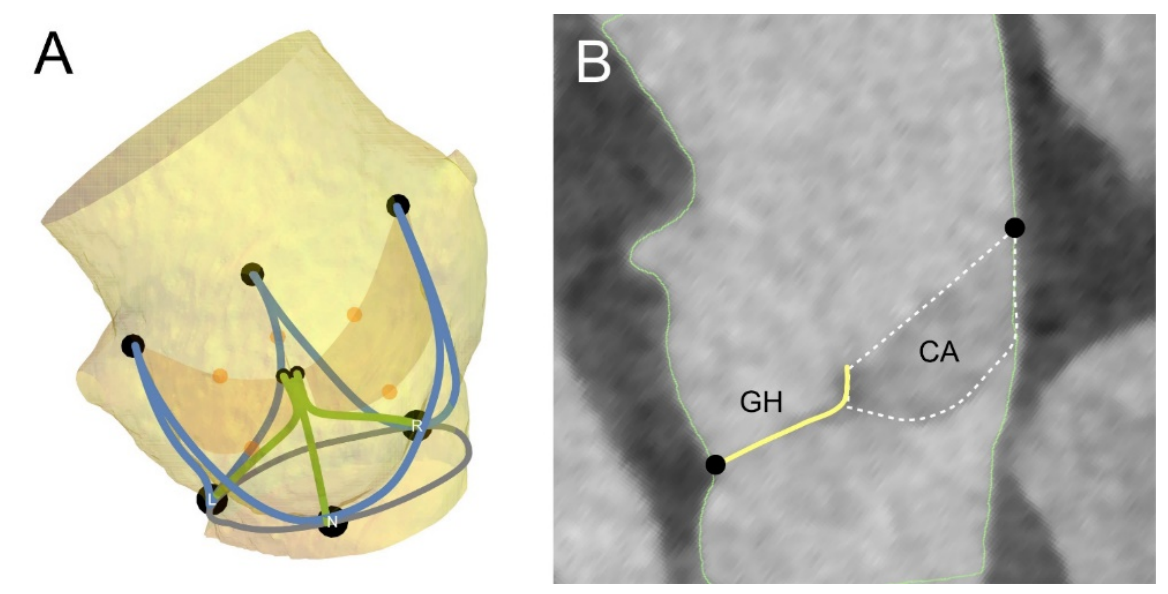
Figure 1. A: The lowest points of leaflet attachments in the nadirs of sinuses of Valsalva $(\mathrm{R}, \mathrm{L}, \mathrm{N})$ were marked on the segmented aortic root and were used to define the annular plane. The highest points of the three commissures were also marked and used to define the sinutubular plane. Next spline tool was used to trace leaflet attachment lines, geometric heights, annular and sinutubular perimeters and leaflet coaptation areas. B: Example of geometric height $(\mathrm{GH})$ and coaptation area $(\mathrm{CA})$ measurement on CTA.
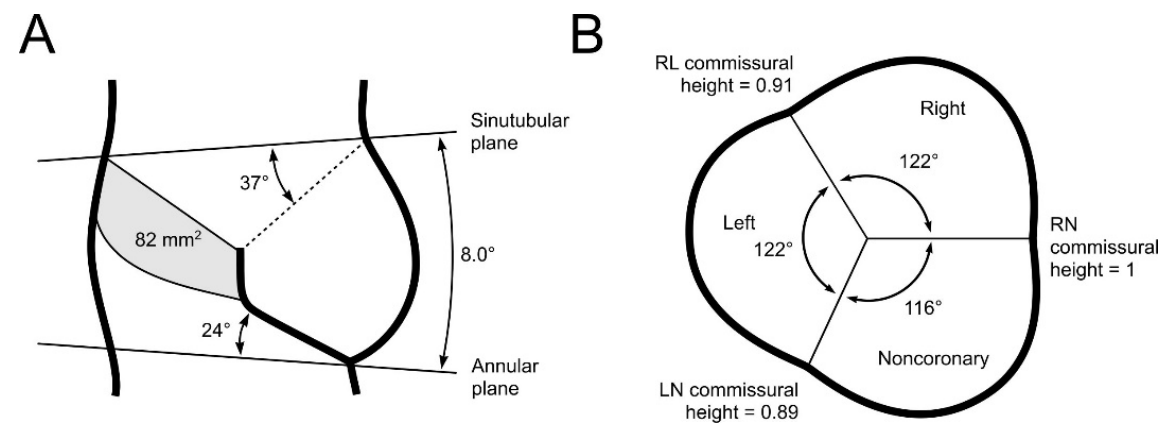

Figure 2. Graphical summary of measured aortic valve data. A: mean coaptation surface between two adjacent leaflets of $82 \mathrm{~mm}^{2}$. Mean free margin to sinutubular plane angle of $37^{\circ}$, mean leaflet belly to annular plane of $24^{\circ}$ and mean angle between sinutubular and annular planes of $8^{\circ}$ B: angles occupied by individual leaflets relative to sinutubular plane (left $122^{\circ}$, right $122^{\circ}$ and noncoronary $116^{\circ}$ ). Also note the relative heights of commissures, $\mathrm{RN}$ commissure being the highest.
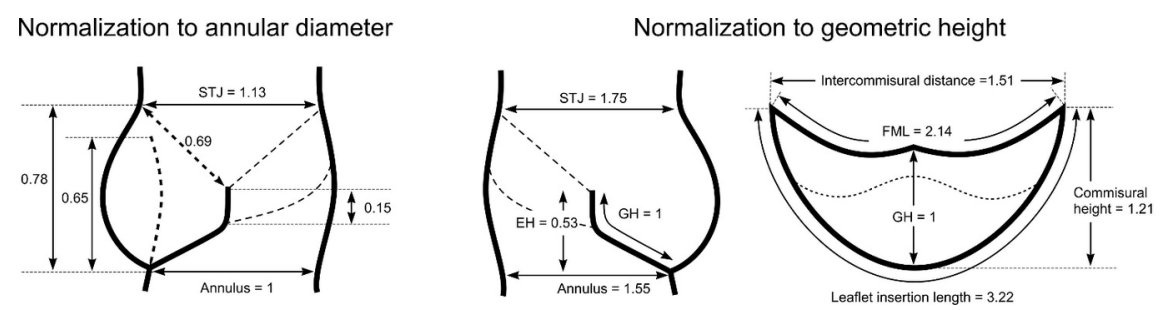

Figure 3. Mean leaflet and root dimensions normalized to either mean annulus diameter or to mean geometric height to allow comparison to published data by Swanson and Clark ${ }^{5}$ and De Kerchove et al ${ }^{6}$. STJ sinutubular junction, GH - geometric height, EH - effective height, FML - free margin length.

\section{References}

1. Lansac E, Di Centa I, Sleilaty G, et al. An aortic ring: from physiologic reconstruction of the root to a standardized approach for aortic valve repair. J Thorac Cardiovasc Surg. 2010;140(6 Suppl):S28-35; discussion S45-51.

2. Takahashi D, Shiiya N, Washiyama N, Yamashita K. Valve-sparing aortic root replacement for a prolapsing asymmetric valve. Interact Cardiovasc Thorac Surg. 2017;24(3):464-465.

3. Kunihara T, Aicher D, Rodionycheva S, et al. Preoperative aortic root geometry and postoperative cusp configuration primarily determine long-term outcome after valve-preserving aortic root repair. $J$ Thorac Cardiovasc Surg. 2012;143(6):1389-1395.

4. Schafers HJ, Bierbach B, Aicher D. A new approach to the assessment of aortic cusp geometry. $J$ Thorac Cardiovasc Surg.2006;132(2):436-438.

5. Swanson M, Clark RE. Dimensions and geometric relationships of the human aortic valve as a function of pressure. Circ Res.1974;35(6):871-882. 
6. De Kerchove L, Momeni M, Aphram G, et al. Free margin length and coaptation surface area in normal tricuspid aortic valve: an anatomical study. Eur J Cardiothorac Surg. 2018;53(5):1040-1048.

7. Schafers HJ, Schmied W, Marom G, Aicher D. Cusp height in aortic valves. J Thorac Cardiovasc Surg. 2013;146(2):269-274.

8. Izawa Y, Mori S, Tretter JT, et al. Normative Aortic Valvar Measurements in Adults Using Cardiac Computed Tomography- A Potential Guide to Further Sophisticate Aortic Valve-Sparing Surgery. Circ J. 2021;85(7):1059-1067.

9. Komiya T, Shimamoto T, Nonaka M, Matsuo T. Is small cusp size a limitation for aortic valve repair? Eur J Cardiothorac Surg.2019;56(3):497-502.

10. Tamer S, Mastrobuoni S, van Dyck M, et al. Free margin length and geometric height in aortic root dilatation and leaflet prolapse: implications for aortic valve repair surgery. Eur J Cardiothorac Surg. 2020;57(1):124-132.

11. Vollebergh FE, Becker AE. Minor congenital variations of cusp size in tricuspid aortic valves. Possible link with isolated aortic stenosis. Br Heart J. 1977;39(9):1006-1011.

12. Yang DH, Kim DH, Handschumacher MD, et al. In vivo assessment of aortic root geometry in normal controls using 3D analysis of computed tomography. Eur Heart J Cardiovasc Imaging. 2017;18(7):780-786.

13. Youssefi P, Zacek P, Debauchez M, Lansac E. Isolated Tricuspid Aortic Valve Repair With Double Annuloplasty: How I Teach It. Ann Thorac Surg. 2019;108(4):987-994.

14. Youssefi P, Zacek P, Debauchez M, Lansac E. Valve-Sparing Aortic Root Replacement Using the Remodeling Technique With Aortic Annuloplasty: Tricuspid Valves With Repair of Specific Lesion Sets: How I Teach It. Ann Thorac Surg. 2019;107(6):1592-1599. 